\title{
METÁFORAS, ANALOGIAS E COMPARAÇÕES NO PENSAMENTO ATORMENTADO DE FERDINAND DE SAUSSURE
}

\author{
GUSTAVO AUGUSTO FONSECA SILVA*
}

\begin{abstract}
"Nós estamos (...) profundamente convencidos de que qualquer um que ponha o pé no terreno da língua está, pode-se dizer, abandonado por todas as analogias do céu e da terra" (SAUSSURE, 2004, p. 189). “(...) a linguagem (é) um objeto que fica fora de qualquer comparação e $n a \tilde{o}$ classificado, nem no espírito dos linguistas, nem no espírito dos filósofos" (SAUSSURE, 2004, p. 219).
\end{abstract}

RESUMO: Neste artigo, investigam-se os usos que Ferdinand de Saussure fez de metáforas, de analogias e de comparações tanto nos manuscritos reunidos nos Escritos de linguística geral quanto no Curso de linguística geral. O objetivo ao fazê-lo é mostrar que, mais do que as rasuras e lacunas dos manuscritos, são as imagens e as figuras a que recorre Saussure em seus textos que revelam as suas dúvidas e hesitações em busca de uma teoria de linguística geral. Com essa reanálise das analogias, metáforas e comparações feitas por Saussure, pretende-se lançar um novo olhar não apenas sobre o seu legado, mas também sobre o fato de ele não ter publicado os resultados de suas reflexões sobre a linguagem.

Palavras-chave: Ferdinand de Saussure; busca de uma teoria de linguística geral; metáforas; analogias e comparações no Curso de linguística geral e nos Escritos de linguística geral.

ABSTRACT: This article investigates how Ferdinand de Saussure used metaphors, analogies, and comparisons both in the collection of manuscripts Writings in General Linguistics and in Course in General Linguistics, demonstrating how images and pictures Saussure used in his texts are more capable of revealing his questions and hesitations while searching for a theory in general linguistics than the blots and gaps in his manuscripts. Such reanalysis of the metaphors, the analogies, and the comparisons Saussure created intends to shed light to a new point of view not only over his legacy, but also over the fact that he did not publish the results of his thoughts on language.

Keywords: Ferdinand de Saussure; search for a general linguistics theory; metaphors, analogies, and comparisons in Course in General Linguistics and in Writings in General Linguistics.

*Universidade Federal de Minas Gerais (UFMG), Belo Horizonte, MG, Brasil. fonsecaugusto@ hotmail.com 


\section{INTRODUÇÃO}

A descoberta de manuscritos inéditos de Ferdinand de Saussure em 1996 num anexo de sua residência em Genebra gerou a expectativa entre os pesquisadores de sua obra de que com aqueles textos finalmente seria revelado o verdadeiro teor de suas ideias linguísticas e, assim, resolvidas muitas das controvérsias relativas a seu pensamento. Passados mais de 20 anos, porém, o que se vê é que, em vez de ajudar a solucionar os grandes problemas exegéticos do Curso de linguística geral, os próprios manuscritos se tornaram motivo de embates entre os saussurianos, sendo difícil encontrar em suas análises o mínimo consenso sobre o legado daquele que é considerado o fundador da linguística moderna. Entre as polêmicas suscitadas pelos manuscritos, uma é particularmente importante por dizer respeito à questão de eles invalidarem ou não o Curso de linguística geral como obra de Saussure. Na opinião de Simon Bouquet, que organizou e editou os manuscritos com Rudolf Engler, publicando-os em 2002 nos Escritos de linguística geral, a resposta é afirmativa. Em sua Introdução à leitura de Saussure, de 1997, Bouquet argumenta que os organizadores do Curso, Charles Bally e Albert Sechehaye, deformaram o pensamento de Saussure, dando-lhe um caráter pronto, acabado, quando na verdade os manuscritos revelariam um autor tomado por dúvidas, angustiado diante de problemas para os quais não tinha respostas. Ao menos, não respostas que o satisfizessem plenamente.

Em se tratando do fato de Bally e Sechehaye terem apagado do Curso de linguística geral as muitas hesitações e inseguranças de Saussure sobre inúmeras questões linguísticas e epistemológicas, é difícil discordar da posição de Bouquet não apenas à luz dos novos manuscritos, mas também à luz de manuscritos anteriormente publicados, sobretudo nos trabalhos clássicos de Robert Godel (1957), Tullio de Mauro (1972) e de Engler (1968, 1974). Quanto à visão de Bouquet de que o Curso é um texto apócrifo que afasta o leitor do verdadeiro Saussure, sendo portanto recomendável deixá-lo de lado e recorrer exclusivamente aos textos redigidos pelo próprio Saussure, parece sensata a opinião dos saussurianos que julgam exagerada essa postura (e.g. ENGLER, 2004; NORMAND, 2009; PEREIRA DE CASTRO, 2016). Assim, como bem observou Carlos Alberto Faraco (2016a, p. 20), "vamos atingindo agora um ponto de equilíbrio: ler ainda o $C L G(\ldots)$, mas em contraste, em confronto e em diálogo com os manuscritos".

Neste artigo, próprio deste novo momento dos estudos sobre Saussure, reanalisa-se o uso de metáforas, de analogias e de comparações tanto nos manuscritos reunidos nos Escritos de linguística geral quanto no Curso de linguística geral - e, como Claudine Normand, "continuarei, segundo a tradição, a chamá-lo de Saussure" (2009, p. 18). O objetivo ao fazer essa reanálise é explicitar o fato de que, mais do que as rasuras e lacunas dos manuscritos - como defende por exemplo Eliane Silveira (2007) -, são as imagens, as figuras a que recorre Saussure que revelam as suas dúvidas e vacilações em busca de uma teoria de linguística geral. Justamente por isso, a investigação das imagens, das figuras, das analogias feitas por Saussure é da máxima importância para a compreensão 
de seu pensamento porque são elas que sinalizam suas incertezas teóricas, são elas que iluminam ao leitor o "torturado caminho seguido por Saussure" (ibid., p. 112).

\section{UM JOGO DE SIGNOS CHAMADO LÍNGUA}

A alegação de que são as imagens, figuras e analogias feitas por Saussure que indicam suas hesitações ao refletir sobre esse "jogo de signos que se chama língua" (SAUSSURE, 2004, p. 38) é sustentada pelo fragmento intitulado "Sobre as dificuldades da terminologia em linguística ('Chega de figuras!')”, publicado por Engler (1968, 1974) e republicado nos Escritos de linguística geral. Nele, Saussure enfatiza:

Chega de figuras! Assim, nada além de expressões que correspondam às realidades absolutas da linguagem? (...)

Chega de figuras! É um belo programa, que logo se pôs no papel. E o que é preciso para pôr em prática esse preceito? Pouca coisa, simplesmente empregar apenas expressões que correspondam às realidades absolutas da linguagem, classificadas de maneira infalível. (...)

Proscrever a figura é se dizer de posse de todas as verdades, de outro modo você fica radicalmente sem condições de dizer onde começa e onde termina uma metáfora.

(...) Chega de figuras? Assim, nada além de termos que correspondam às realidades absolutas da linguagem? Isso equivale a dizer que as realidades absolutas da linguagem não oferecem mistério para os neogramáticos, que eles as desvendaram para nós (p. 200-201).

Em nota ao fim do primeiro capítulo do Curso, é feita a mesma crítica ao programa de proscrever figuras, ainda que de maneira menos categórica:

A nova escola, cingindo-se mais à realidade, fez guerra à terminologia dos comparatistas e notadamente às metáforas ilógicas de que se servia. Desde então, não mais se ousa dizer: "a língua faz isto ou aquilo" nem falar da "vida da língua" etc., pois a língua não é mais uma entidade e não existe senão nos que a falam. Não seria, portanto, necessário ir muito longe e basta entender-se. Existem certas imagens das quais não se pode prescindir. Exigir que se usem apenas termos correspondentes à realidade da linguagem é pretender que essas realidades não têm nada de obscuro para nós. Falta muito, porém, para isso; também não hesitaremos em empregar, quando se ofereça a ocasião, algumas das expressões que foram reprovadas na época (p. 36).

De fato, foram empregadas tanto no Curso quanto nos manuscritos algumas das expressões que foram reprovadas pelos neogramáticos, com a devida exceção a expressões como "a língua faz isto ou aquilo" e "a vida da língua", utilizadas por comparatistas como August Schleicher e Max Müller, que viam as línguas como organismos que nascem, crescem, definham e morrem, e não como instituições sociais. Mas Saussure não se ateve às velhas expressões. Ciente de que desconhecia as "realidades absolutas da linguagem" e de que não poderia classificá-las de maneira infalível, Saussure também criou expressões e imagens com o intuito de esclarecer os aspectos da linguagem que lhe eram mais obscuros. Além disso, 
valeu-se de um sem-número de comparações com a mesma finalidade. Entre elas, é claro, a comparação entre a língua e o jogo de xadrez.

Essa comparação é feita no Curso pela primeira vez no quinto capítulo da Introdução, "Elementos internos e elementos externos da língua", com a intenção de melhor compreender as diferenças entre a linguística externa e a linguística interna: "Nesse jogo (o xadrez), é relativamente fácil distinguir o externo do interno; o fato de ele ter passado da Pérsia para a Europa é de ordem externa; interno, ao contrário, é tudo quanto concerne ao sistema e às regras" (p. 56). Conforme Saussure (ibid., p. 53), sua definição de língua - "o verdadeiro e único objeto" da ciência linguística (ibid., p. 31) - supõe que se elimine dela tudo o que seja estranho ao "organismo", ao "sistema", ou seja, tudo o que seja do âmbito da linguística externa: as relações entre a história de uma língua e de uma civilização; as relações entre a língua e a história política, etc. Ciente de que não tinha "posse da verdade" de tal eliminação, que não é nada fácil, Saussure recorre à analogia entre a língua e o jogo de xadrez para esclarecer sua posição, já que nesse jogo é muito mais simples distinguir o externo do interno.

Mais à frente, no $\S 4$ do terceiro capítulo da primeira parte do Curso, Saussure compara a autonomia e interdependência do sincrônico com a projeção de um corpo sobre um plano e compara a língua com o tronco de um vegetal. Seu objetivo ao fazê-lo é ilustrar a diferença entre a ordem sincrônica e a ordem diacrônica da língua, sendo esta para ele "um sistema do qual todas as partes podem e devem ser consideradas em sua solidariedade sincrônica" (ibid., p. 128). Nenhuma comparação, porém, na opinião de Saussure, é mais demonstrativa de tal diferença do que aquela entre o jogo da língua e uma partida de xadrez, à qual ele mais uma vez recorre (ibid., p. 130-131) para esclarecer sua posição, pois tampouco tinha "posse da verdade" da diferença entre a ordem sincrônica e a ordem diacrônica da língua. Sintomaticamente, mais adiante, no primeiro capítulo da segunda parte do Curso, intitulada "Linguística sincrônica", Saussure afirma que "é muito mais difícil fazer a linguística estática que a histórica" porque "os fatos de evolução são mais concretos; falam mais à imaginação; as relações que neles se observam se estabelecem entre termos sucessivos que são percebidos sem dificuldades; é cômodo e, com frequência, até divertido acompanhar uma série de transformações" (ibid., p. 145). Não por acaso, no capítulo seguinte, "As entidades concretas da língua", Saussure novamente recorre à analogia entre a língua e o jogo de xadrez (ibid., p. 152) com o objetivo de compreender tais entidades. Tampouco por acaso, no terceiro capítulo da segunda parte do Curso, "Identidades, realidades, valores", Saussure recorre à mesma analogia a fim de entender como são estabelecidos os valores no sistema linguístico (ibid., p. 156).

Fato notório, em vários outros pontos do Curso, Saussure também lança mão da analogia entre a língua e o jogo de xadrez, afirmando por exemplo que os valores tanto das peças de um jogo de xadrez quanto dos termos de uma língua

${ }^{1}$ Deve-se ressaltar que é empregada aqui no Curso uma das expressões dos comparatistas que foram reprovadas pelos neogramáticos, mas sem que tenha sido levada às últimas consequências a analogia entre a língua e um organismo, como o fizeram Schleicher, Müller e Hovelacque, os quais Saussure critica veementemente (e.g. SAUSSURE, 2004, p. 130 e p. 135). 
“dependem (...) de uma convenção imutável: a regra do jogo, que existe antes do início da partida e persiste após cada lance" (p. 130). Mais importante, porém, do que apresentar uma lista exaustiva dos já conhecidos pontos em que Saussure comparou a língua a um jogo de xadrezé observar que as outras tantas comparações estabelecidas por Saussure no Curso e nos manuscritos servem exatamente ao mesmo propósito: tentar esclarecer as "realidades absolutas da linguagem". Um propósito a que Saussure se dedicou obstinadamente por décadas, apesar de estar convicto de que a língua "já se encontra na impossibilidade absoluta de ser (...) uma coisa diretamente captável, pelo nosso espírito, em sua maneira de ser" (2004, p. 189).

\section{EM BUSCA DAS REALIDADES ABSOLUTAS DA LINGUAGEM}

Em sua primeira conferência na Universidade de Genebra, em novembro de 1891, Saussure declarou aos ouvintes: "Não existe objeto comparável à língua, que é um ser muito complexo, e é isso que faz com que todas as comparações e todas as imagens de que nos servimos habitualmente acabem, regularmente, por nos dar uma ideia falsa" (SAUSSURE, 2004, p. 133). No entanto, nenhum instrumento foi mais utilizado por Saussure em sua tentativa desesperançada de captar a língua em sua maneira de ser do que comparações e imagens. Provam esse fato tanto o Curso quanto os manuscritos, que são perpassados por metáforas, analogias e comparações as mais diversas, relativas aos mais diferentes aspectos da linguagem. Entre os textos descobertos em 1996 e reunidos sob a rubrica "Sobre a essência dupla da linguagem", encontram-se, por exemplo, a comparação entre uma figura vocal e um pedaço de pano que se torna um sinal num navio (ibid., p. 38); a comparação entre o sistema da língua e um sistema de sinais marítimos obtidos por meio de bandeiras de diversas cores (ibid., p. 52) e a tão frequente comparação entre a língua e o jogo de xadrez (ibid., p. 63). Já nos textos reunidos na seção "Antigos documentos", vemos Saussure comparar, por exemplo, a língua com as grandes morainas das geleiras (ibid., p. 131-132); a "pretensa sucessão do latim pelo francês" com uma rua muito longa a que se poderia dar um único nome ou vários nomes a frações dela (ibid., p. 143-144) e os idiomas congêneres com geleiras divergentes (ibid., p. 155). No quarto capítulo da Introdução do Curso de linguística geral, por sua vez, Saussure não apenas compara a língua a uma sinfonia (p. 50) como afirma que "a língua existe na coletividade sob a forma de uma soma de sinais depositados em cada cérebro, mais ou menos como um dicionário cujos exemplares, todos idênticos, fossem repartidos entre os indivíduos" (p. 51). No capítulo seguinte, Saussure compara uma vez mais a língua ao jogo de xadrez (p. 55-56), e voltará a fazê-lo em outras partes do livro, como no terceiro capítulo dos "Princípios gerais" (p. 130-131) e no segundo capítulo da seção "Linguística sincrônica" (p. 142).

Essa pequena lista de imagens e comparações encontradas nos manuscritos e no Curso, por si só, parece o bastante para desabonar a afirmação de Bouquet de que "a reflexão saussuriana sobre uma reforma dos fundamentos teóricos da linguística 
consegue abandonar em grande parte as imagens e os neologismos" (2016, p. 71). $\mathrm{Na}$ verdade, a reflexão saussuriana sobre a reforma dos fundamentos teóricos da linguística é alicerçada em imagens e comparações, além de ser pontuada por neologismos. Logo no início da seção "Sobre a essência dupla da linguagem", por exemplo, Saussure recorre a comparações na tentativa de entender o que constitui uma identidade linguística e de explicitar por que é tão árdua a tarefa que se impõe ao linguista de apreender essas identidades. Conforme Saussure (2004, p. 21-22), uma identidade linguística implica a associação de dois elementos heterogêneos: uma ideia, que é psicológica, e uma forma, que é física. Para Saussure, é justamente devido à heterogeneidade dos elementos constituintes das identidades linguísticas que é difícil compreender a sua natureza. A fim de tornar mais claro esse entrave com que se depara o linguista, Saussure observa que acharíamos fácil determinar a espécie química de uma barra de ferro, de ouro, de cobre, bem como determinar a espécie zoológica de um cavalo, de um boi, de um carneiro, mas não acharíamos nada fácil determinar a "espécie" de um "conjunto bizarro" de uma barra de ferro presa a um cavalo, de uma barra de ouro em cima de um boi ou de um carneiro com um enfeite de cobre. Afinal, trata-se neste segundo caso da associação de dois elementos heterogêneos. "É precisamente diante dessa tarefa absurda que é preciso que o linguista entenda que está, de repente e antes de tudo, colocado", afirma Saussure (ibid., p. 22). O linguista, completa Saussure (ibid.), "ignora o que constitui o objeto formal do seu estudo e de suas classificações, a saber, exclusivamente, o ponto de junção dos dois domínios”. Para reforçar sua posição, Saussure pondera que as identidades linguísticas não são comparáveis a um corpo químico simples nem a uma combinação química, mas são comparáveis a uma mistura química como a mistura do azoto e do oxigênio no ar, já que o ar não é mais ar sem um elemento ou outro, mas um independe do outro. Mais à frente, Saussure volta a abordar os dois domínios do objeto formal dos estudos linguísticos apresentando novas dificuldades sobre a questão:

\footnotetext{
Há, na língua, um lado físico e um lado psíquico. Mas o erro irremissível, que se traduzirá de mil maneiras em cada parágrafo de uma gramática, é acreditar que o lado psíquico é a ideia enquanto o lado físico é o som, a forma, a palavra.

As coisas são um pouco mais complicadas do que isso.

Não é verdade, é profundamente errado imaginar que há oposição entre o som e a ideia, que são, ao contrário, indissoluvelmente unidos pelo nosso espírito.

A oposição [ ]

Assim, há, de um lado, uma palavra (entidade física), de outro sua significação (entidade psíquica). Há, na língua, um lado físico e um lado psíquico. Essa verdade de sentido comum tem um sentido que deve ser absolutamente preciso para quem quer estudar a língua: trata-se de saber quais são as coisas a serem dispostas no domínio físico e quais são as coisas a serem dispostas no domínio psíquico.

A cômoda distinção tradicional, e desastrosa, que anula, na realidade, no germe, todo estudo racional da língua, é supor que o lado psíquico é, simplesmente, a IDEIA ou a significação, enquanto que o lado físico [ ] (ibid., p. 60).
}

Em um dos manuscritos descobertos em 1996 que foram reunidos na seção "Novos item", Saussure explicita uma vez mais que o linguista ignora o ponto de junção dos dois domínios do objeto formal do seu estudo e de suas classificações: 
Se existe uma verdade a priori, e que exija apenas bom senso para se estabelecer, é que se há realidades psicológicas, e se há realidades fonológicas, nenhuma das duas séries separadas seria capaz de dar origem, por um instante, ao menor fato linguístico.

Para que haja fato linguístico, é necessária a união das duas séries, mas uma união de um gênero particular - da qual seria absolutamente vão querer explorar, por um instante que fosse, as características, ou dizer de antemão o que ela será (ibid., p. 93).

Contrariando-se, porém, Saussure tentou explorar a união das séries psicológica e fonológica recorrendo à analogia da folha de papel, também presente na seção "Novos item":

Quando se diz "signo", imaginando-se, falsamente, que ele poderá, depois, ser separado à vontade de "significação" e que designa apenas a "parte material", nada se teria a aprender, senão considerando que o sujeito tem um limite material, como sua lei absoluta, e que esse limite já é, em si mesmo, um "signo", um portador de significação. É, portanto, inteiramente ilusório opor, em qualquer instante, o signo à significação. São duas formas do mesmo conceito do espírito, visto que a significação não existiria sem um signo e que ela é apenas a experiência às avessas do signo, assim como não se pode cortar uma folha de papel sem cortar o avesso e o direito desse papel com a mesma tesourada (ibid., p. 87-88).

No Curso, todo o segundo capítulo da segunda parte, "As entidades concretas da língua", é dedicado à questão dos dois domínios do signo, já denominados significante e significado. Dada a dificuldade do tema, Saussure volta a recorrer à comparação entre "essa unidade de duas faces" com uma composição química, após descartar como pouco satisfatória a comparação entre a entidade linguística e a unidade da pessoa humana, composta de alma e de corpo: “(...) a água por exemplo; é uma combinação de hidrogênio e de oxigênio; tomados separadamente, nenhum desses elementos tem as propriedades da água" (p. 148). Em seguida, Saussure também descarta a comparação entre os signos linguísticos e os signos visuais, já que estes são materiais e coexistem no espaço visual sem se confundir, enquanto aqueles são abstratos e precisam ser identificados no espírito do sujeito falante pela junção entre o aspecto fônico e o aspecto significativo:

Quando ouvimos uma língua desconhecida somos incapazes de dizer como a sequência de sons deve ser analisada; é que essa análise se torna impossível se se levar em conta somente o aspecto fônico do fenômeno linguístico. Mas quando sabemos que significado e que papel cumpre atribuir a cada parte da sequência, vemos então tais partes se desprenderem umas das outras e a fita amorfa partir-se em fragmentos; ora, essa análise nada tem de material (ibid.).

Com base nessas considerações, Saussure define a unidade linguística como "uma porção de sonoridade que, com exclusão do que precede e do que segue na cadeia falada, é significante de um certo conceito" (2014, p. 148). Trata-se, no entanto, de uma definição muito vaga, que em nada auxilia o linguista a delimitar as unidades linguísticas, como se depreende do método de delimitação apresentado no $\S 2$ do mesmo segundo capítulo da segunda parte do Curso e das dificuldades práticas da delimitação explicitadas no $\S 3$. Não por coincidência, ao fim do capítulo, Saussure volta a comparar a língua ao jogo de xadrez, ponderando: “(...) assim como o jogo de xadrez está todo inteiro na combinação das diferentes peças, 
assim também a língua tem o caráter de um sistema baseado completamente na oposição de suas unidades concretas" (ibid., p. 152). Mas completa, ciente de ainda ignorar o que constitui o objeto formal do seu estudo e de suas classificações: "Não podemos dispensar-nos de conhecê-las, nem dar um passo sem recorrer a elas; e, no entanto, sua delimitação é um problema tão delicado que nos perguntamos se elas, as unidades, existem de fato" (ibid).

\section{UMA TEORIA INACABADA}

No capítulo seguinte do Curso, "Identidades, realidades, valores", Saussure passa à investigação desses três conceitos, diretamente dependentes da noção de unidade, como afirma logo no primeiro parágrafo. Após apresentar o conceito de "identidade" e explicitar as dificuldades de delimitá-lo, Saussure mais uma vez se vale de comparações para tentar esclarecê-lo: compara "identidade" com os expressos "Genebra-Paris, 8h45 da noite", que partem com 24 horas de intervalo; com uma rua que é arrasada e reconstruída, sem que subsista nada de material da antiga; com um traje que é roubado e reencontrado em uma loja. Feitas as comparações, declara: "O vínculo entre os dois empregos da mesma palavra não se baseia na identidade material nem na exata semelhança de sentido, mas em elementos que cumprirá investigar e que nos farão chegar bem perto da verdadeira natureza das unidades linguísticas" (p. 155). Bem perto, mas não atingi-las...

Em relação ao conceito de "realidade", Saussure chama a atenção para o fato de não ser nada óbvia a tradicional classificação das palavras em substantivos, adjetivos, verbos, etc., já que não é nada óbvio quais elementos concretos ou abstratos da língua podem ser chamados de realidades sincrônicas. Tendo em vista esse obstáculo teórico, Saussure afirma: “(...) a linguística trabalha incessantemente com conceitos forjados pelos gramáticos, e sem saber se eles correspondem realmente a fatores constitutivos do sistema da língua. Mas como sabê-lo? E se forem fantasmas, que realidade opor-lhes?" (ibid.). Sem apresentar uma solução ao problema, Saussure passa à noção de "valor", que não apenas "recobre as de unidade, de entidade concreta e de realidade" (p. 156) como é o "aspecto primordial" das unidades (p. 157). Para explicar o conceito de "valor" - sobre o qual já vinha refletindo desde o fim do século 19, como o comprovam alguns de seus manuscritos (cf. SAUSSURE, 2004, p. 27-30) -, Saussure se vale de novo da comparação entre a língua e o jogo de xadrez, ressaltando que o valor de uma entidade concreta não está em sua materialidade, assim como o valor do cavalo no xadrez independe da peça em si.

Adiante, no capítulo "O valor linguístico", Saussure parte da constatação de que a língua é um sistema de valores constituído por ideias e sons para voltar a abordar o problema da junção desses dois elementos heterogêneos, chamando a atenção para o fato "de certo modo misterioso" de "o 'pensamento-som' implicar divisões e de a língua elaborar suas unidades constituindo-se entre duas massas amorfas" (p. 159). Ainda sem a posse dessa verdade, Saussure imediatamente se utiliza de uma comparação para tentar aproximar-se dela: "Imaginemos o ar 
em contato com uma capa de água: se muda a pressão atmosférica, a superfície da água se decompõe numa série de divisões, vale dizer, de vagas; são essas ondulações que darão uma ideia da união e, por assim dizer, do acoplamento do pensamento com a matéria fônica" (ibid.). Não satisfeito, Saussure também retoma a comparação entre a língua e uma folha de papel para tentar esclarecer a junção entre as ideias e os sons.

Mais à frente, após reconhecer novamente que não podia captar diretamente as entidades concretas ou unidades da língua, Saussure elege as palavras como objeto de estudo, por acreditar que elas dão uma ideia aproximada do que seja uma unidade linguística. Feito isso, passa a mostrar as diferenças entre valor e significação, argumentando que os dois conceitos não são sinônimos. Conforme Saussure, os valores são sempre constituídos (1) por uma coisa dessemelhante, que pode ser trocada por outra cujo valor resta determinar e (2) por coisas semelhantes que se podem comparar com aquela cujo valor está em causa. Tentando se fazer entender, Saussure apresenta mais uma comparação:

(...) para determinar o que vale a moeda de cinco francos, cumpre saber: $1^{\circ}$ - que se pode trocála por uma quantidade determinada de uma coisa diferente, por exemplo pão; $2^{\circ}$ - que se pode compará-la com um valor semelhante do mesmo sistema, por exemplo uma moeda de um franco ou uma moeda de algum outro sistema (um dólar etc.). Do mesmo modo, uma palavra pode ser trocada por algo dessemelhante: uma ideia; além disso, pode ser comparada com algo da mesma natureza: outra palavra (p. 162).

Em seguida, Saussure elenca exemplos para ilustrar seu ponto de vista, começando pela contraposição entre o francês mouton e o inglês sheep, que têm a mesma significação, mas não o mesmo valor, já que ao se referir à carne servida à mesa o inglês diz mutton, e não sheep, enquanto o francês usa o mesmo termo para se referir tanto ao animal quanto à carne a ser comida. Sem se limitar às palavras, Saussure cita ainda exemplos referentes ao valor de plural e de flexão em diferentes línguas, concluindo que, em vez de ideias dadas de antemão, são valores que emanam do sistema. Assim, "quando se diz que os valores correspondem a conceitos, subentende-se que são puramente diferenciais, definidos não positivamente por seu conteúdo, mas negativamente por suas relações com os outros termos do sistema. Sua característica mais exata é ser o que os outros não são" (p. 164).

Ao fim do capítulo, Saussure retoma o conceito de unidade, afirmando que o que é verdadeiro do valor também é verdadeiro da unidade. Além disso, afirma que o que se chama de "fato de gramática" responde à definição de unidade, já que exprime uma oposição de termos. Para exemplificar sua argumentação, Saussure cita a formação do plural alemão do tipo Nacht : Nächte. De acordo com Saussure, esses termos, tomados isoladamente, não são nada, o que mostra que tudo é oposição. Tentando se fazer mais claro, Saussure elabora mais uma comparação: “(...) pode-se expressar a relação Nacht : Nächte por uma fórmula algébrica $a / b$ em que $a$ e $b$ não são termos simples, mas resultam cada um de um conjunto de relações. A língua é, por assim dizer, uma álgebra que teria somente termos complexos" (p. 169). 
No capítulo seguinte, "Relações sintagmáticas e relações associativas", Saussure não apenas continua empregando o conceito de unidade como se utiliza de mais uma comparação para tentar explicá-lo, logo após ter apresentado os conceitos de sintagma e de relações associativas:

(...) uma unidade linguística é comparável a uma parte determinada de um edifício, uma coluna, por exemplo; a coluna se acha, de um lado, numa certa relação com a arquitrave que a sustém; essa disposição de duas unidades igualmente presentes no espaço faz pensar na relação sintagmática; de outro lado, se a coluna é de ordem dórica, ela evoca a comparação mental com outras ordens (jônica, coríntia etc.), que são elementos não presentes no espaço: a relação é associativa (p. 172).

No sexto capítulo da segunda parte do Curso, "Mecanismo da língua", Saussure conclui, com base nas relações sintagmáticas e associativas, que "na língua tudo se reduz a diferenças, mas tudo se reduz também a agrupamentos" (p. 177). Para esclarecer sua afirmação, Saussure formula mais uma comparação: "Esse mecanismo, que consiste num jogo de termos sucessivos, se assemelha ao funcionamento de uma máquina cujas peças tenham todas uma ação recíproca, se bem que estejam dispostas numa só dimensão" (ibid.). Trata-se, claro, de uma comparação com a qual Saussure lança luz sobre um dos múltiplos aspectos da língua, ciente de que "em nenhuma parte se nos oferece integral o objeto da linguística" (ibid., p. 40). Além disso, estando atento ao fato de que a língua também se caracteriza como "uma instituição atual e um produto do passado" (p. 40), Saussure recorreria a outras comparações com o intuito de iluminar esse outro aspecto do objeto da linguística.

No terceiro capítulo dos "Princípios gerais" do Curso, Saussure propõe dividir a linguística em duas partes exatamente devido à duplicidade da língua, esse "mecanismo que continua a funcionar, não obstante as deteriorações que lhe são causadas" (p. 128): uma linguística evolutiva e uma linguística estática, também denominadas de linguística sincrônica e linguística diacrônica. Conforme Saussure, é sincrônico tudo que se relacione com o lado estático da língua e diacrônico tudo que é relativo a seu lado evolutivo, ou seja, "sincronia e diacronia designarão respectivamente um estado de língua e uma fase de evolução" (p. 123). Para melhor justificar essa divisão do trabalho do linguista, Saussure emprega mais uma comparação geológica:

A primeira coisa que surpreende quando se estudam os fatos da língua é que, para o indivíduo falante, a sucessão deles no tempo não existe: ele se acha diante de um estado. Também o linguista que queira compreender esse estado deve fazer tabula rasa de tudo quanto produziu e ignorar a diacronia. Ele só penetra na consciência dos indivíduos que falam suprimindo o passado. A intervenção da história apenas lhe falsearia o julgamento. Seria absurdo desenhar um panorama dos Alpes focalizando-o simultaneamente de vários picos do Jura; um panorama deve ser focalizado de um só ponto. O mesmo para a língua: não podemos descrevê-la nem fixar normas para o seu uso sem nos colocarmos num estado determinado. Quando o linguista segue a evolução da língua, semelha o observador em movimento, que vai de uma a outra extremidade do Jura para anotar os deslocamentos da perspectiva (ibid.). 
E, para explicar o conceito de estado de língua, Saussure volta a comparar a língua com uma partida de xadrez, afirmando que "uma posição de jogo corresponde de perto a um estado de língua" (p. 130). Mas o que é, de fato, um estado de língua? E como delimitar tais estados? Em sua terceira conferência na Universidade de Genebra, de novembro de 1891, Saussure já expunha toda a dificuldade de responder a essas questões, com as quais se ocuparia pelo resto da vida:

(...) existem apenas estados de língua que são, perpetuamente, a transição entre o estado da véspera e o do dia seguinte; querer reunir um certo número de estados de língua sob um nome como latim ou francês é a mesma operação e tem exatamente o mesmo valor de opor o século 19 ao 18 ou ao 12. São vagos pontos de referência, sem a pretensão de evocar a ideia de uma ordem finita de coisas, e menos ainda de descartar a ideia da ordem pouco diferente que precedia e que se seguirá (SAUSSURE, 2004, p. 144).

Sem ter encontrado uma solução satisfatória ao problema de determinar os estados de língua, Saussure se limita no Curso a apresentar caracterizações vagas desse conceito, afirmando por exemplo que "um estado de língua não é um ponto, mas um espaço de tempo, mais ou menos longo, durante o qual a soma de modificações ocorridas é mínima. Pode ser de 10 anos, uma geração, um século e até mais” (p. 146). Sem surpresa alguma, Saussure também se vale de uma comparação para tentar apanhar o conceito de estado de língua, dizendo que "estudar um estado de língua vem a ser, praticamente, desdenhar as transformações pouco importantes, do mesmo modo que os matemáticos desprezam as quantidades infinitesimais em certas operações, tal como no cálculo de logaritmos" (ibid.). Dada essa condição para estudar um estado de língua, Saussure admite: “A noção de estado de língua não pode ser senão aproximativa. Em linguística estática, como na maior parte das ciências, nenhuma demonstração é possível sem uma simplificação convencional dos dados" (ibid.). Nada indica, porém, que Saussure tenha ficado satisfeito com esse arremedo de solução ao problema fundamental de determinar os estados de língua. Tampouco há indícios de que Saussure tenha se contentado em trabalhar com dados simplificados, ainda que isso seja praxe na maior parte das ciências. Muito menos se encontram evidências de que Saussure estivesse convencido de ter elaborado uma teoria de linguística geral, como acredita Loïc Depecker, que afirma com base na leitura dos manuscritos que tal teoria "aparece, afinal, em toda a sua coerência, sem que Saussure tenha podido chegar a um belo livro" (2012, p. 169). Na realidade, o que se encontram são testemunhos da angústia de Saussure, já no fim da vida, diante dos impasses com que se defrontava em suas reflexões sobre a linguagem. Entre esses testemunhos, nenhum é tão eloquente nem tão citado - quanto o de Léopold Gautier, um dos alunos do último curso de linguística geral ministrado por Saussure, que anotou uma conversa particular com o professor, datada de 6 de maio de 1911, na qual ele lhe confidenciou:

Vejo-me diante de um dilema: ou expor o assunto em toda a sua complexidade e confessar todas as minhas dúvidas, o que não pode convir para um curso que deve ser matéria de exame, ou fazer 
algo simplificado, mais bem adaptado a um auditório de estudantes que não são linguistas. Mas a cada passo me vejo retido por escrúpulos. ${ }^{2}$

Dessa maneira, "devemos ter sempre em mente que o próprio Saussure, até o fim da vida, recusou-se a publicar qualquer coisa que fosse sobre linguística geral. Ele estava convicto de que não havia alcançado o ponto em que se sentisse confiante de que tal publicação fosse possível" (BOUISSAC, 2012, p. 194). Além disso, Saussure "insistia que existiam (...) muitos problemas que permaneciam sem solução e que a única coisa de que ele estava certo era que qualquer coisa que tivesse sido publicada até então sobre linguística geral era, em sua opinião, de pouco valor" (ibid.). Uma opinião que Saussure expressou com toda a clareza em suas "Notas para um livro de linguística geral":

(...) nós não consideramos a linguística como uma ciência em que há um bom princípio de divisão a encontrar mas, fora uma ou duas reservas, como uma ciência que procura juntar, em um único todo, dois objetos completamente discordantes desde o princípio, persuadindo-se de que eles formam um único objeto. O mais grave é que nossa ciência está satisfeita com essa associação, não parece nada atormentada com o vago sentimento de que há alguma coisa errada na base; não manifesta nenhum mal-estar diante das concepções as mais oblíquas que aceita a cada dia, sente-se, mesmo, tão de posse de seu objeto que não tem nenhuma dificuldade para extrair, de tempos em tempos, dessa desordem geral de ideias, teorias da linguagem, apresentadas com total candura (SAUSSURE, 2004, p. 194).

Assim, "mais do que um questionamento profundo do $C L G$, a leitura dos manuscritos, com suas hesitações, suas rasuras, suas repetições e também seus silêncios, obriga a renunciar à imagem de uma teoria acabada; mas isso seria, a bem dizer, a impressão que se poderia retirar da leitura do próprio Curso" (NORMAND, 2009, p. 109). De fato, o que se retira da leitura tanto do Curso quanto dos manuscritos - inclusive das notas preparatórias para os cursos de linguística geral - é "um pensamento inacabado, atormentado, em que as fronteiras são demarcadas não sem certo grau de hesitação" (CRUZ, 2016, p. 48). Evidência maior disso é o uso constante que Saussure faz de imagens e de comparações tentando se aproximar das "realidades absolutas da linguagem" e da língua em particular, com sua "irritante duplicidade que faz com que jamais seja alcançada" (SAUSSURE, 2004, p. 186).

\section{UMA PROFISSÃO DE FÉ}

Em 1916, ano da publicação póstuma do Curso, Gautier lembrava-se de seu falecido professor como "um senhor honrado e educado, aparentemente cansado e sonhador, com um toque de perplexidade e tristeza ansiosa" (BOUISSAC, 2012, p. 62). Se não se tem essa impressão de Saussure lendo o Curso, nenhuma outra surge da leitura de seus manuscritos, nos quais transbordam as "dolorosas hesitações da reflexão de Saussure" (ARRIVÉ, 2010, p. 51, n. 12). Entre os

${ }^{2}$ Citado pelo professor Isaac Nicolau Salum em seu prefácio à edição brasileira do Curso (SAUSSURE, 2014, p. 15). 
primeiros textos reunidos sob a rubrica "Sobre a essência dupla da linguagem", por exemplo, encontra-se um fragmento intitulado "Quatro pontos de vista". Nele, Saussure expõe aqueles que considera os quatro únicos pontos de vista legítimos da linguagem: (1) o ponto de vista do estado de língua em si mesmo - ou seja, o ponto de vista sincrônico; (2) o ponto de vista das identidades transversais - ou seja, o ponto de vista diacrônico; (3) "o ponto de vista ANACRÔNICO, artificial, intencional e puramente didático, da PROJEÇÃO de uma morfologia (ou de um 'estado de língua antiga') sobre uma morfologia (ou sobre um outro estado de língua posterior)"; (4) "o ponto de vista HISTÓRICO da fixação de dois estados de língua sucessivos, tomados cada qual em si mesmo, em primeiro lugar, e sem subordinação de um ao outro, seguida da explicação". Feita essa categorização da linguagem, Saussure lamenta o fato de que seus colegas prestavam atenção quase que somente ao segundo e terceiro pontos de vista, havendo "uma verdadeira ausência de reflexão por parte dos autores" (ibid., p. 25) quanto aos outros pontos. A fim de mudar essa situação, Saussure iria se dedicar visceralmente por décadas para legitimar o estudo sincrônico da língua a par do estudo diacrônico, ainda que estivesse dolorosamente ciente do caráter quixotesco de seu projeto:

(...) uma profissão de fé: assim como estamos convencidos, com ou sem razão, de que por fim será preciso tudo reduzir, teoricamente, aos nossos quatro pontos de vista legítimos, que repousam sobre dois pontos de vista necessários, assim também duvidamos de que alguma vez seja possível estabelecer, com pureza, a quádrupla, ou, ao menos, a dupla terminologia que seria necessária (SAUSSURE, 2004, p. 25).

O efeito dessa profissão de fé no trabalho de Saussure é absolutamente desconcertante. Se por um lado a certeza do fracasso não o impediu de continuar em busca de uma teoria de linguística geral, por outro tal certeza o impossibilitou de levar a cabo a grande obra de sua vida.

\section{CONSIDERAÇÕES FINAIS}

Neste artigo, foram investigados alguns dos recorrentes usos que Saussure fez de metáforas, de analogias e de comparações tanto em seus manuscritos quanto no Curso de linguística geral tendo por objetivo mostrar como esses recursos sinalizam as dúvidas, inseguranças e hesitações do linguista genebrino em sua busca desalentada por uma teoria de linguística geral. Ao fim desta discussão, pode-se afirmar com segurança que, apesar de a análise apresentada reiterar a crítica feita por Bouquet a Bally e Sechehaye de que ambos deformaram o pensamento de Saussure no Curso ao lhe dar um caráter pronto e acabado, a mesma análise também aproxima o Saussure dos manuscritos do Saussure do Curso, desabonando assim a exortação feita por Bouquet de que essa obra deveria ser ignorada pelos interessados nas verdadeiras ideias saussurianas. Essa conclusão, é claro, não surpreenderia aqueles que leem o Curso em contraste, em confronto e em diálogo com os manuscritos. Afinal, como puderam constatar esses leitores, o que tais documentos de fato revelaram - ou melhor, confirmaram - não foram 
as verdadeiras ideias de Saussure, e sim o caráter verdadeiramente provisório, inconclusivo, de suas reflexões sobre a linguagem.

\section{REFERÊNCIAS}

ARRIVÉ, Michel. Em busca de Ferdinand de Saussure. São Paulo: Parábola, 2010.

BOUISSAC, Paul. Saussure: um guia para os perplexos. Petrópolis: Vozes, 2012.

BOUQUET, Simon. Introdução à leitura de Saussure. São Paulo: Cultrix, 2016.

CRUZ, Marcio Alexandre. Por que (não) ler o Curso de linguística geral depois de um século? In: FARACO, Carlos Alberto (Org.). O efeito Saussure: cem anos do Curso de linguística geral. São Paulo: Parábola, 2016, p. 25-48.

CRUZ, M. A.; PIOVEZANI, Carlos; TESTENOIRE, Pierre-Yves (Orgs.). Saussure, o texto e o discurso: cem anos de heranças e recepções. São Paulo: Parábola, 2016.

DEPECKER, Loïc. Compreender Saussure a partir dos manuscritos. Petrópolis: Vozes, 2012.

ENGLER, Rudolf. Cours de linguistique générale. Wiesbaden: Otto Harrassowitz, 1968, t. I.

ENGLER, Rudolf. Cours de linguistique générale. Wiesbaden: Otto Harrassowitz, 1974, t. II.

ENGLER, Rudolf. The making of the Cours de linguistique générale. In: SANDERS, C. (Org.). Saussure. Cambridge: Cambridge University Press, 2004, p. 47-58.

FARACO, Carlos Alberto. Apresentação. In: FARACO, Carlos Alberto (Org.). O efeito Saussure: cem anos do Curso de linguística geral. São Paulo: Parábola, 2016a, p. 7-24.

FARACO, Carlos Alberto (Org.). O efeito Saussure: cem anos do Curso de linguística geral. São Paulo: Parábola, 2016b.

GODEL, Robert. Les sources manuscrites du Cours de linguistique générale de F. de Saussure. Genebra: Libraire Droz, 1957.

MAURO, Tullio de. Notes. In: SAUSSURE, F. de. Cours de linguistique générale. Paris: Payot \& Rivages, 1972.

NORMAND, Claudine. Saussure. São Paulo: Estação Liberdade, 2009.

PEREIRA DE CASTRO, Maria Faustina. Ler os manuscritos saussurianos com o Curso de linguística geral. In: FARACO, Carlos Alberto (Org.). O efeito Saussure: cem anos do Curso de linguística geral. São Paulo: Parábola, 2016, p. 49-71.

SAUSSURE, Ferdinand de. Curso de linguística geral. 28. ed. São Paulo: Cultrix, 2014.

SAUSSURE, Ferdinand de. Escritos de linguística geral. São Paulo: Cultrix, 2004.

SILVEIRA, Eliane. As marcas do movimento de Saussure na fundação da linguística. Campinas: Mercado das Letras, 2007. 